NBSIR 88-3761

\title{
Predicting Formaldehyde Concentrations in Manufactured Housing Resulting From Medium-Density Fiberboard
}

Samuel Silberstein

U.S. DEPARTMENT OF COMMERCE

National Bureau of Standards

National Engineering Laboratory

Center for Building Technology

Building Environment Division

Gaithersburg, MD 20899

April 1988

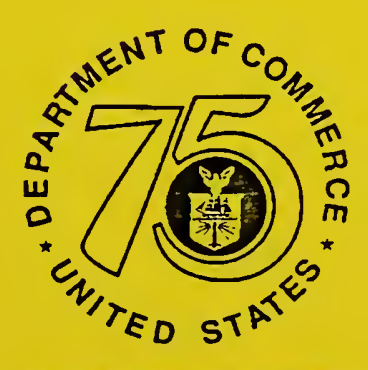

75 Yoars Silmulating America's Progress
1913-1988

Prepared for:

U.S. Department of Housing and Urban Development

Washington, DC 



\section{PREDICTING FORMALDEHYDE \\ CONCENTRATIONS IN MANUFACTURED \\ HOUSING RESULTING FROM \\ MEDIUM-DENSITY FIBERBOARD}

Samuel Silberstein

U.S. DEPARTMENT OF COMMERCE

National Bureau of Standards

National Engineering Laboratory

Center for Building Technology

Building Environment Division

Gaithersburg, MD 20899

April 1988

Prepared for:

U.S. Department of Housing and Urban Development Washington, DC

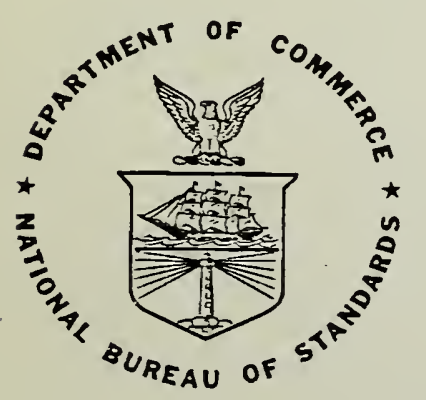

U.S. DEPARTMENT OF COMMERCE, C. William Verity, Secretary

NATIONAL BUREAU OF STANDARDS, Ernest Ambler, Director 



\section{PREDICTING FORMALDEHYDE CONCENTRATIONS IN MANUFACTURED HOUSING RESULTING FROM MEDIUM-DENSITY FIBERBOARD}

\section{Introduction}

In 1984, HUD issued Manufactured Home Construction and Safety Standards limiting formaldehyde emissions of particleboard and plywood paneling that was manufactured using urea-formaldehyde resins for use in manufactured homes [1]. The standards specified that the formaldehyde concentration of particleboard present in a measuring chamber at a loading (that is, the exposed pressed-wood product surface area per unit volume of the space) of $0.13 \mathrm{ft}^{2} / \mathrm{ft}^{3}\left(0.4265 \mathrm{~m}^{2} / \mathrm{m}^{3}\right)$ be limited to 300 $\mathrm{ppb}$, and that the concentration of plywood present in a measuring chamber at a loading of $0.29 \mathrm{ft}^{2} / \mathrm{ft}^{3}\left(0.9514 \mathrm{~m}^{2} / \mathrm{m}^{3}\right)$ be limited to $200 \mathrm{ppb}$. The chamber, which is specified in the standard, must be operated at $25^{\circ} \mathrm{C}$ and $50 \% \mathrm{RH}$, with an air exchange rate of $0.5 \mathrm{~h}^{-1}$. Because concentration is invariant with volume or pressed-wood product surface area as long as loading is maintained constant, the same loadings of these products would result in the same formaldehyde concentrations in manufactured homes, provided that temperature, relative humidity and air exchange rate are kept constant.

The other major pressed-wood product manufactured from urea-formaldehyde resins, but not covered by the standards, is medium-density fiberboard (mdf). The purpose of this study is to predict the formaldehyde concentration of a chamber containing only medium-density fiberboard, so that if particleboard and plywood meeting the emissions limits of the HUD standards were added to the chamber at the maximum loadings permitted by the standards, the formaldehyde concentration would remain below $400 \mathrm{ppb}$.

Formaldehyde concentrations predicted for each type of pressed-wood product may not simply be added together to predict the concentration resulting from a combination of products. For example, if both particleboard and plywood were present at the loadings and concentrations permitted by the HUD standards, then the resulting concentration at $25^{\circ} \mathrm{C}$, $50 \% \mathrm{RH}$, and an air exchange rate of $0.5 \mathrm{~h}^{-1}$ would be $330 \mathrm{ppb}$, which is far lower than the sum of $300 \mathrm{ppb}$ and $200 \mathrm{ppb}$. In fact, the plywood could be said to make a nearly negligible contribution to the concentration. This is because the formaldehyde emission rate decreases with increasing formaldehyde concentration. The emission rate of plywood at $300 \mathrm{ppb}$ formaldehyde is far lower than at $200 \mathrm{ppb}$, so it contributes much less than an additional $200 \mathrm{ppb}$ formaldehyde to an atmosphere already containing $300 \mathrm{ppb}$.

In order to study the effects of combinations of pressed-wood products, the concentrations of individual products must first be expressed in terms of formaldehyde surface emission rates. According to Fick's diffusion law, the surface emission rate is linear in concentration with negative slope. Oak Ridge National Laboratory (ORNL) [2] developed models that extrapolate the linear regression coefficients for the Fick's Law expression at standard conditions of $23^{\circ} \mathrm{C}, 50 \% \mathrm{RH}$, and $100 \mathrm{ppb}$ concentration, to any other combination of temperature, relative humidity 
and concentration. A simple mass-balance indoor air quality model developed at the National Bureau of Standards (NBS) [3] can then be used to obtain concentrations resulting from combinations of products having different emission rates.

Validation studies of the ORNL and mass-balance indoor air quality models were performed at NBS [3]. These studies showed that the models performed well for particleboard and mdf. They did not perform well for plywood; however, the model's predictions for plywood emission rates were higher than those actually obtained so that they still provide an upper bound.

The ORNL and indoor air quality models will be used to give mdf concentrations that satisfy the requirements specified above. These concentrations will be translated into permissible surface emission rates, which will depend on mdf loading. (A small loading will give the same concentration with a higher surface emission rate than a larger loading.) Next, a sensitivity study will be performed. The effects of small variations in temperature, relative humidity, and air exchange rate on formaldehyde concentrations and surface emission rates due to mdf, will be analyzed.

\section{Methods}

Assume in all that follows that the external formaldehyde concentration = $0 \mathrm{ppb}$. The external concentration is that outside the chambers and outside the home. Further, let subscripts 1, 2, and 3 refer to particleboard underlayment, hardwood-plywood paneling, and mdf, respectively.

From Fick's diffusion law:

$$
\operatorname{ser}_{i} / \operatorname{ser}_{i, 23,50,100}=a_{i}-b_{i} \cdot C
$$

where

$\mathrm{C}=$ formaldehyde concentration, $\mathrm{ppb}$.

$\operatorname{ser}_{i}=$ formaldehyde surface emission rate, $\mathrm{mg} / \mathrm{m}^{2} \cdot \mathrm{h}$.

$\operatorname{ser}_{i}, 23,50,100=\operatorname{ser}_{i}$ at $23^{\circ} \mathrm{C}, 50 \% \mathrm{RH}$ and $\mathrm{C}=100 \mathrm{ppb}$.

ORNL empirically determined the coefficients $a_{i}$ and $b_{i}$ to be as follows:

$$
\begin{aligned}
& b_{i}=[1+B \cdot(T-296.15)] \cdot[1+E \cdot(R H-50)] /\left(C_{b s t d}-100\right) \\
& a_{i}=b_{i} \cdot \exp \left[-c \cdot\left(T^{-1}-296.15^{-1}\right)\right] \cdot(R H / 50) A \cdot C_{b s t d}
\end{aligned}
$$

where

$A, B, C, E$, and $C_{b s t d}$ are given in table 1 for each type of pressed wood product.

$\mathrm{T}=$ absolute temperature, $\mathrm{K}$.

$\mathrm{RH}=$ relative humidity, $\%$. 
According to the NBS indoor air quality model:

$$
\Sigma 1_{i} \cdot \operatorname{ser}_{i}=C \cdot g \cdot A I
$$

where

$$
\begin{aligned}
& \mathrm{C}=\text { formaldehyde concentration at equilibrium, } \mathrm{ppb} . \\
& \mathrm{l}_{\mathrm{i}}=\text { loading }=\text { area } \mathrm{i} / \mathrm{V}, \mathrm{m}^{2} / \mathrm{m}^{3} \text {. } \\
& \text { area } \mathrm{a}_{\mathrm{i}} \text { exposed surface area of boards of class } \mathrm{i}, \mathrm{m}^{2} . \\
& \mathrm{V}=\text { volume of space, } \mathrm{m}^{3} \text {. } \\
& \mathrm{g}=\text { formaldehyde concentration conversion factor from } \mathrm{ppb} \text { to } \\
& \mathrm{mg} / \mathrm{m}^{3}=1.228 \times 10^{-3} \mathrm{mg} / \mathrm{m}^{3} \cdot \mathrm{ppb} \text {. } \\
& \mathrm{AI}=\text { air exchange rate, } \mathrm{h}^{-1} \text {. }
\end{aligned}
$$

[Unspecified summations should be taken from $i=1$ to $i=3$. ]

Equation 4 gives the relationship between $\operatorname{ser}_{3}$ and $l_{3}$ :

$$
1_{3} \cdot \operatorname{ser}_{3}=C \cdot g \cdot A I-l_{1} \cdot \operatorname{ser}_{1}-l_{2} \cdot \operatorname{ser}_{2}
$$

ser $_{1}$ and ser 2 can be calculated from equations 2 and 3 . For any value of $1_{3}$, ser3,23,50,100 may be calculated from ser3, as determined by equation 5 , and from $a_{3}$ and $b_{3}$, as determined by equations 2 and 3 :

$$
\operatorname{ser}_{3}, 23,50,100=\operatorname{ser}_{3} /\left(a_{3}-b_{3} \cdot c\right)
$$

In the present report, $\mathrm{C}$ is always taken to be $400 \mathrm{ppb}$ in the home.

The mdf measuring chamber concentration can be calculated for any combination of mdf loading and $\operatorname{ser}_{3}$ :

$$
1_{3} \cdot \operatorname{ser}_{3}=C \cdot g \cdot A I
$$

According to equation 1:

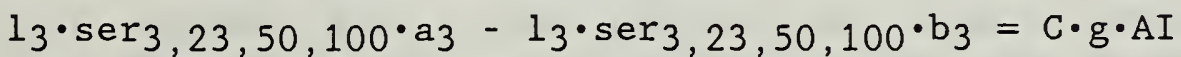

$$
\begin{aligned}
& C=\left(1_{3} \cdot \operatorname{ser} 3,23,50,100 \cdot a_{3}\right) /\left(1_{3} \cdot \operatorname{ser} 3,23,50,100 \cdot b_{3}+g \cdot A I\right)
\end{aligned}
$$

\section{Results}

\subsection{Mdf concentrations and emission rates}

Suppose that the temperature, relative humidity, and air exchange rate of a manufactured home are $25^{\circ} \mathrm{C}, 50 \%$, and $0.5 \mathrm{~h}^{-1}$, respectively. Suppose that particleboard and plywood are present at the maximum loadings permitted by the HUD standards. Their formaldehyde emission rates are such that when the two types of pressed-wood products are tested separately in chambers, their concentrations are as large as permitted, i. e. $300 \mathrm{ppb}$ and $200 \mathrm{ppb}$, respectively. Then the two pressed-wood 
products in combination would give a concentration of $330 \mathrm{ppb}$. How much mdf could be added to the building in order to just reach $400 \mathrm{ppb}$ ? The answer is that any combination of mdf that results in a chamber-test concentration of $300 \mathrm{ppb}$ would result in a total home concentration of $400 \mathrm{ppb}$, provided that the loading, air exchange rate, temperature and relative humidity are the same as for the chamber. This still does not answer the question of how much mdf can be added to the building. This depends on the loading and on the surface emission rate, which can be conveniently expressed as ser23,50,100. The higher the loading one wishes to permit, the smaller must be ser $23,50,100$.

The results discussed in the previous paragraph are shown in figure 1 and table 2. The curves are iso-concentration curves; each point on each curve yields an mdf chamber-test concentration as indicated. The combinations of loadings and ser23,50,100's for the curve marked "300 ppb" would result in a total concentration of $400 \mathrm{ppb}$ in the presence of particleboard and plywood. The curve marked "400 ppb" shows the permitted combinations of loadings and ser23,50,100's in the absence of formaldehyde emitters other than mdf. Both the house and chamber-test concentrations would be $400 \mathrm{ppb}$ in this case. The curve marked "200 ppb" shows permitted combinations of loadings and ser23,50,100's if one wishes to incorporate a margin of error, as discussed below in the section on sensitivity. The chamber-test concentration would be $200 \mathrm{ppb}$ in this case, and the house concentration would remain at $400 \mathrm{ppb}$ even if the temperature were slightly higher than $25^{\circ} \mathrm{C}$, the relative humidity slightly higher than 50\%, and the air exchange rate slightly higher than $0.5 \mathrm{~h}^{-1}$.

\section{Sensitivity}

One might want to ensure that the formaldehyde concentration of a home remains below $400 \mathrm{ppb}$ for temperatures greater than $25^{\circ} \mathrm{C}$, relative humidities greater than 50\%, and air exchange rates smaller than $0.5 \mathrm{~h}^{-1}$. In that case, one would choose combinations of mdf loadings and ser23,50,100's that yield lower formaldehyde concentrations in chamber tests than required to meet the $400 \mathrm{ppb}$ limit. For example, figure 2 shows that to ensure that the concentration remains below $400 \mathrm{ppb}$ at a loading of $0.1 \mathrm{~m}^{2} / \mathrm{m}^{3}$ at $26^{\circ} \mathrm{C}$, one would require that ser $23,50,100$ be kept below $1 \mathrm{mg} / \mathrm{m}^{2} \cdot \mathrm{h}$. For $25^{\circ} \mathrm{C}$, ser $23,50,100$ would only have to be kept below $2 \mathrm{mg} / \mathrm{m}^{2} \cdot \mathrm{h}$. At $27^{\circ} \mathrm{C}, 50 \mathrm{r} \mathrm{RH}$, and an air exchange rate of $0.5 \mathrm{~h}^{-1}$, it is impossible to keep the concentration below $400 \mathrm{ppb}$ because the permitted loadings of other pressed- wood products already result in a greater concentration before addition of any mdf.

Table 3 and figure 3 show the sensitivity of chamber-test concentrations to temperature. The curve shows that the mdf chamber-test concentration changes by about $35 \mathrm{ppb}$ for a change of $1^{\circ} \mathrm{C}$ to either direction from $25^{\circ} \mathrm{C}$. This means that if excursions of $1^{\circ} \mathrm{C}$ in the chamber temperature commonly occur or cannot be distinguished by the measurement system, one should limit the chamber concentration to about $260 \mathrm{ppb}$ rather than 300 $\mathrm{ppb}$. 
Table 4 and figure 4 show the sensitivity of chamber-test concentrations to relative humidity. The curve shows that the mdf chamber-test concentration changes by about $50 \mathrm{ppb}$ for a change of $5 \%$ to either direction from $50 \% \mathrm{RH}$. This means that if excursions of $5 \%$ in chamber relative humidity commonly occur or cannot be distinguished by the measurement system, one should limit the chamber concentration to about $250 \mathrm{ppb}$ rather than $300 \mathrm{ppb}$.

Table 5 and figure 5 show the sensitivity of chamber-test concentrations to air exchange rate. The curve shows that the mdf chamber-test concentration changes by about $30 \mathrm{ppb}$ for a change of $0.1 \mathrm{~h}^{-1}$ to either direction from $0.5 \mathrm{~h}^{-1}$. This means that if excursions of $0.1 \mathrm{~h}^{-1}$ in the chamber air exchange rate commonly occur or cannot be distinguished by the measurement system, one should limit the chamber concentration to about $270 \mathrm{ppb}$ rather than $300 \mathrm{ppb}$.

These results show that excursions of about $50 \mathrm{ppb}$ can be expected from divergences of the temperature, relative humidity and air exchange rate from their specified values. Table 6 shows the effect of two combinations of such divergences. For example, suppose that instead of being at the specified conditions, the chamber is at the first combination of conditions in table 6 . If the chamber concentration were limited to $150 \mathrm{ppb}$ at those conditions, then that would be equivalent to a concentration of $300 \mathrm{ppb}$ if at specified conditions (last line of table $6)$. If one obtained a concentration of $300 \mathrm{ppb}$ instead of $150 \mathrm{ppb}$, then the equivalent concentration at the specified conditions would be well over $100 \mathrm{ppb}$ higher than $300 \mathrm{ppb}$ at the specified conditions. The divergence at the second combination of conditions would not be as great. Neither of these combinations of conditions would be difficult to obtain during a chamber test. Thus, in order to ensure that mdf emissions truly result in a concentration of $300 \mathrm{ppb}$ at specified conditions, one might want to allow for a margin of error and permit a concentration on the order of $200 \mathrm{ppb}$. Figure 1 shows the relationship between mdf loading and ser23,50,100 in order to obtain a chamber-test concentration of 200 $\mathrm{ppb}$.

5. References

[1] Department of Housing and Urban Development, "Manufactured home construction and safety standards," Fed. Reg. 49, 31996-32008, 1984.

[2] T. G. Matthews, T. J. Reed, B. J. Tromberg, K. W. Fung, C. V. Thompson, J. O. Simpson, and A. R. Hawthorne, "Modeling and Testing of Formaldehyde Emission Characteristics of Pressed-Wood Products," Report no. 18 to CPSC, Oak Ridge National Laboratory Report no. TM $9867,1985$. 
[3] R. A. Grot, S. Silberstein, and K. Ishiguro, "Validation of Models for Predicting Formaldehyde Concentrations in Residences due to Pressed Wood Products -- Phase I," National Bureau of Standards Interagency Report no. 85-3255, Gaithersburg, MD, 1985.

Table 1. Coefficients for the ORNL model

$$
\text { pressed-wood product }
$$

particleboard underlayment hardwood-plywood paneling medium-density fiberboard

$$
\mathrm{c}
$$$$
9,400
$$

6,500

5,000
A

$$
\begin{gathered}
\text { Cbstd } \\
\text { ppb }
\end{gathered}
$$

0.37

0.66

1.90
360

410

900
$B$
$K^{-1}$

$\overbrace{}^{E}-1$

0.025

0.053

0.090
0.016 .

0.029

0.000 
Table 2. Mdf loading vs. $\operatorname{ser}_{23}, 50,100$ in the presence of particleboard and plywood

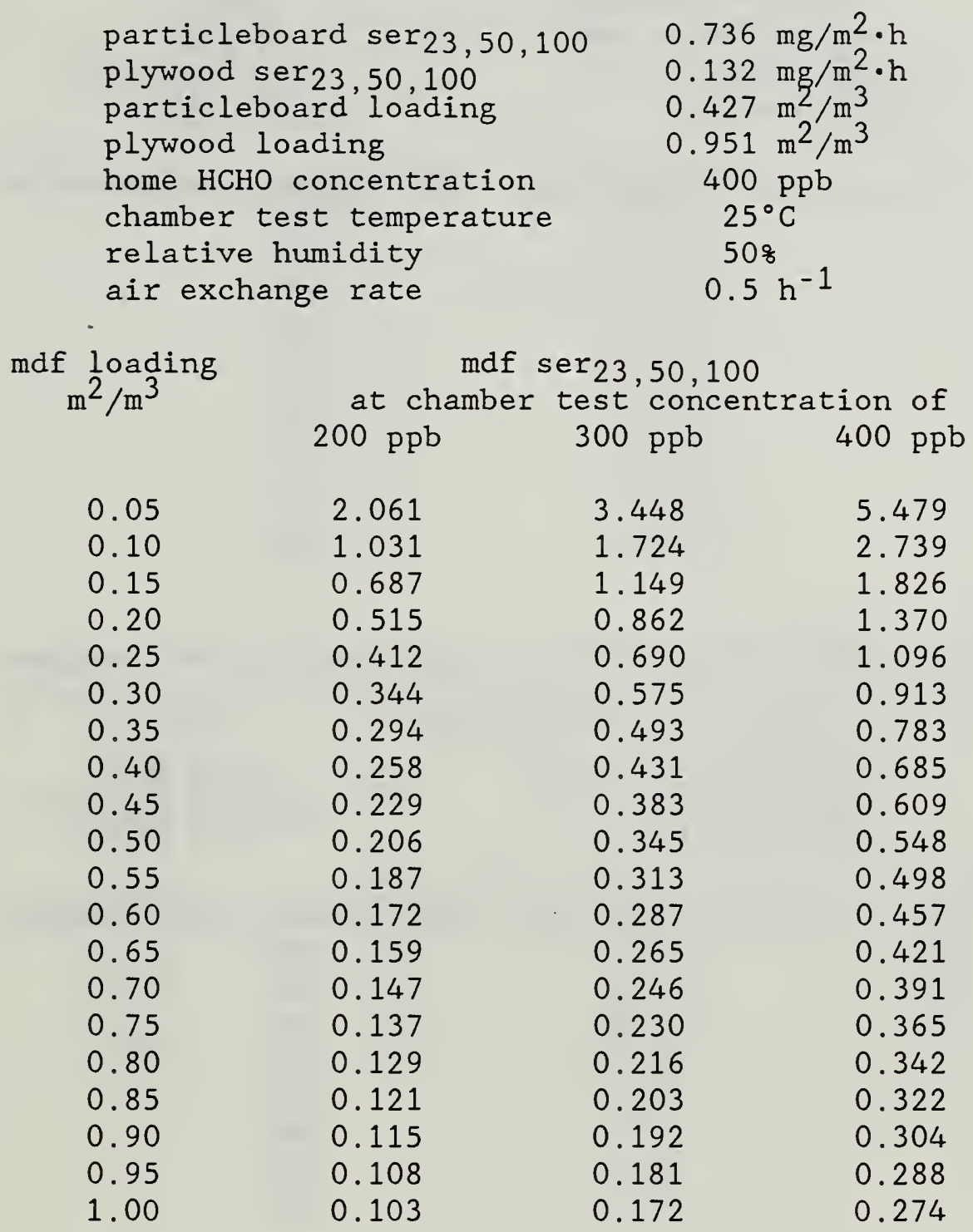


Table 3. Temperature vs. mdf chamber test concentration

$\begin{array}{cc}\text { relative humidity } & 508 \\ \text { air exchange rate } & 0.5 \mathrm{~h}^{-1} \\ \text { mdf ser23,50,100 } & 1.724 \mathrm{mg} / \mathrm{m}^{2} \cdot \mathrm{h} \\ \text { mdf loading } & 0.1 \mathrm{~m}^{2} / \mathrm{m}^{3} \\ \text { temperature } & \text { mdf chamber concentration } \\ { }^{\circ} \mathrm{C} & \mathrm{ppb} \\ 22.5 & 220 \\ 23.0 & 230 \\ 23.5 & 250 \\ 24.0 & 260 \\ 24.5 & 280 \\ 25.0 & 300 \\ 25.5 & 310 \\ 26.0 & 330 \\ 26.5 & 350\end{array}$

Table 4. Relative humidity vs. mdf chamber test concentration

$\begin{array}{cc}\begin{array}{lc}\text { chamber test temperature } \\ \text { air exchange rate }\end{array} & 25^{\circ} \mathrm{C} \\ \text { mdf ser23,50,100 } & 0.5 \mathrm{~h}^{-1} \\ \text { mdf loading } & 1.724 \mathrm{mg} / \mathrm{m}^{2} \cdot \mathrm{h} \\ & 0.1 \mathrm{~m}^{2} / \mathrm{m}^{3} \\ \text { relative humidity } & \text { mdf chamber concentration } \\ 8 & \mathrm{ppb} \\ 35.0 & 150 \\ 40.0 & 190 \\ 45.0 & 240 \\ 50.0 & 300 \\ 55.0 & 350 \\ 60.0 & 420 \\ 65.0 & 490\end{array}$


Table 5. Air exchange rate vs. mdf chamber test concentration

$$
\begin{array}{cc}
\begin{array}{cc}
\text { chamber test temperature } \\
\text { relative humidity }
\end{array} & 25^{\circ} \mathrm{C} \\
\text { mdf ser23,50,100 } & 1.724 \mathrm{mg} / \mathrm{m}^{2} \cdot \mathrm{h} \\
\text { mdf loading } & 0.1 \mathrm{~m}^{2} / \mathrm{m}^{3} \\
& \\
\text { air exchange rate } & \text { mdf chamber concentration } \\
\text { h-1 } & \mathrm{ppb} \\
0.30 & 410 \\
0.35 & 370 \\
0.40 & 340 \\
0.45 & 320 \\
0.50 & 300 \\
0.55 & 280 \\
0.60 & 260 \\
0.65 & 240 \\
0.70 & 230
\end{array}
$$

\begin{tabular}{|c|c|c|c|c|c|c|}
\hline $\begin{array}{l}\operatorname{mdf} \\
\operatorname{mdf}\end{array}$ & $\begin{array}{l}\operatorname{ser}_{23,50,100} \\
\text { loading }\end{array}$ & & & $\begin{array}{l}724 \\
0.1\end{array}$ & $/ \mathrm{m}^{2} \cdot \mathrm{h}$ & \\
\hline temp & $\mathrm{RH}$ & air & exchange & rate & mdf chamber & conc \\
\hline${ }^{\circ} \dot{\mathrm{C}}$ & 8 & & $h^{-1}$ & & $\mathrm{ppb}$ & \\
\hline 24.0 & 40 & & 0.60 & & 150 & \\
\hline 24.5 & 45 & & 0.55 & & 210 & \\
\hline 25.0 & 50 & & 0.50 & & 300 & \\
\hline
\end{tabular}

Table 6. Combined effect on mdf chamber concentration of temperature, relative humidity and air exchange rate 


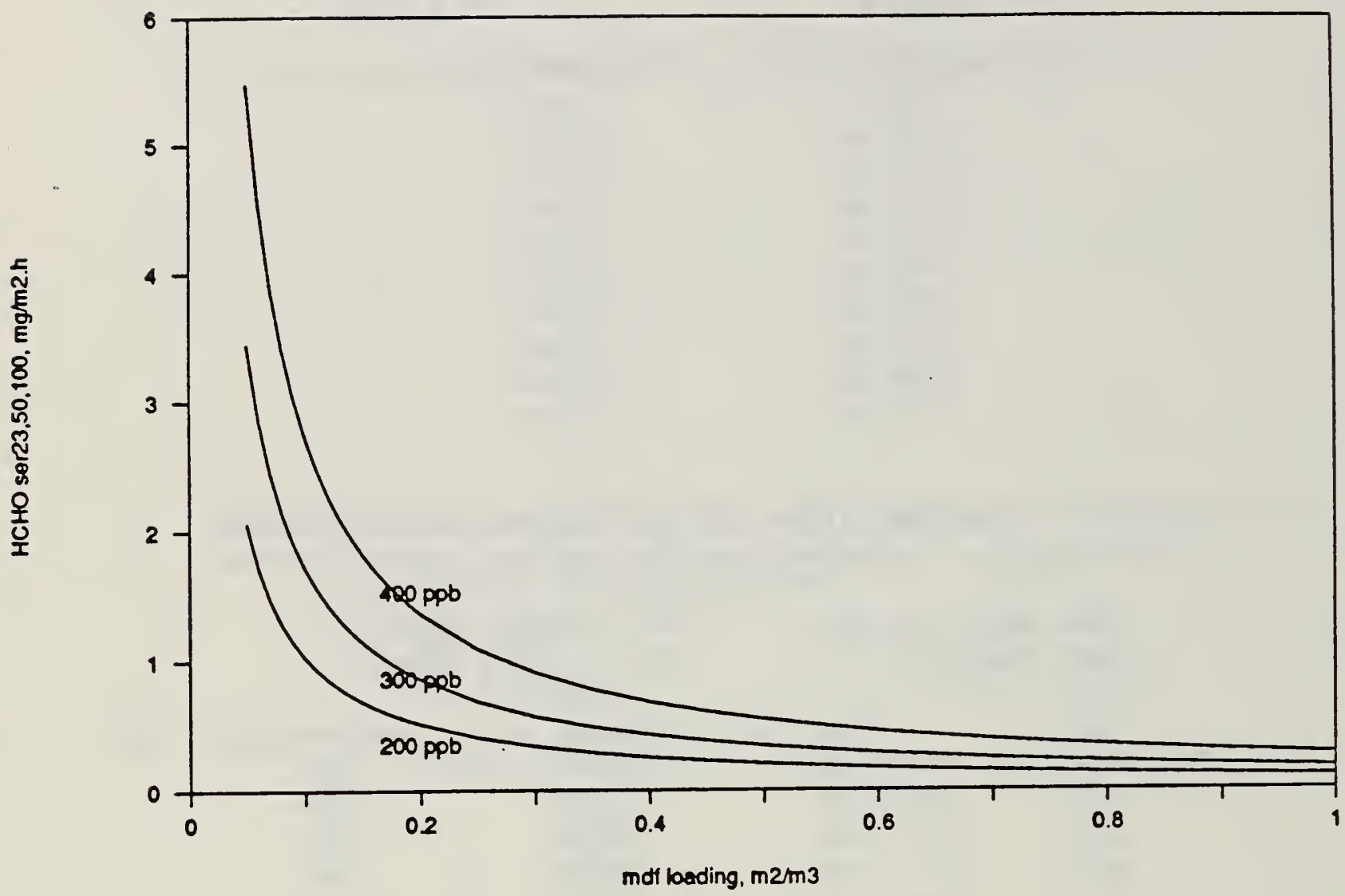

Figure 1. Isoconcentration curves (200, 300, and $400 \mathrm{ppb}$ ) showing the combinations of $\mathrm{mdf}$ loading and ser23,50,100 required to obtain the indicated chamber-test concentrations in the absence of any other formaldehyde emitters. The same combination of mdf loading and ser23,50,100 would presumably result in the indicated concentration in a manufactured home in the absence of other emitters. The temperature is $25^{\circ} \mathrm{C}$, the relative humidity is $50 \%$, and the air exchange rate is $0.5 \mathrm{~h}^{-1}$. Points on the curve marked "300 $\mathrm{ppb} "$ would result in a total concentration of $400 \mathrm{ppb}$, either in chambers or manufactured homes, in the presence of the maximum loadings of particleboard and plywood permitted by the HUD standards. Particleboard and plywood are assumed to emit formaldehyde at the maximum rate permitted by the HUD standards. 


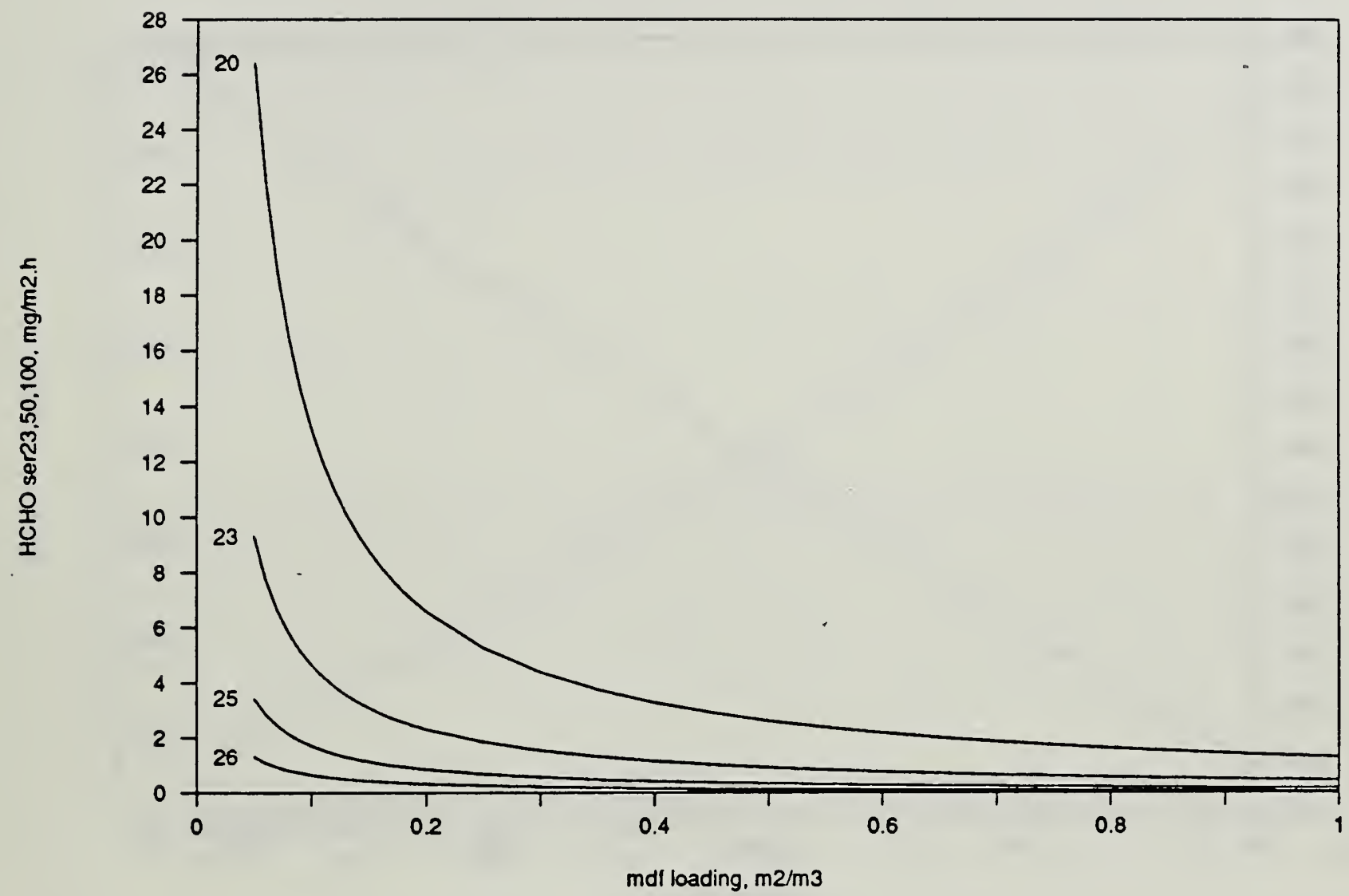

Figure 2. Isoconcentration curves showing combinations of mdf loading and ser23,50,100 required to obtain a concentration of $400 \mathrm{ppb}$ at the indicated temperatures (in ${ }^{\circ} \mathrm{C}$ ). The relative humidity is 508 , and the air exchange rate is $0.5 \mathrm{~h}^{-1}$. Particleboard and plywood are assumed to be present at the maximum loadings, and to emit formaldehyde at the maximum rates, permitted by the HUD standards. 


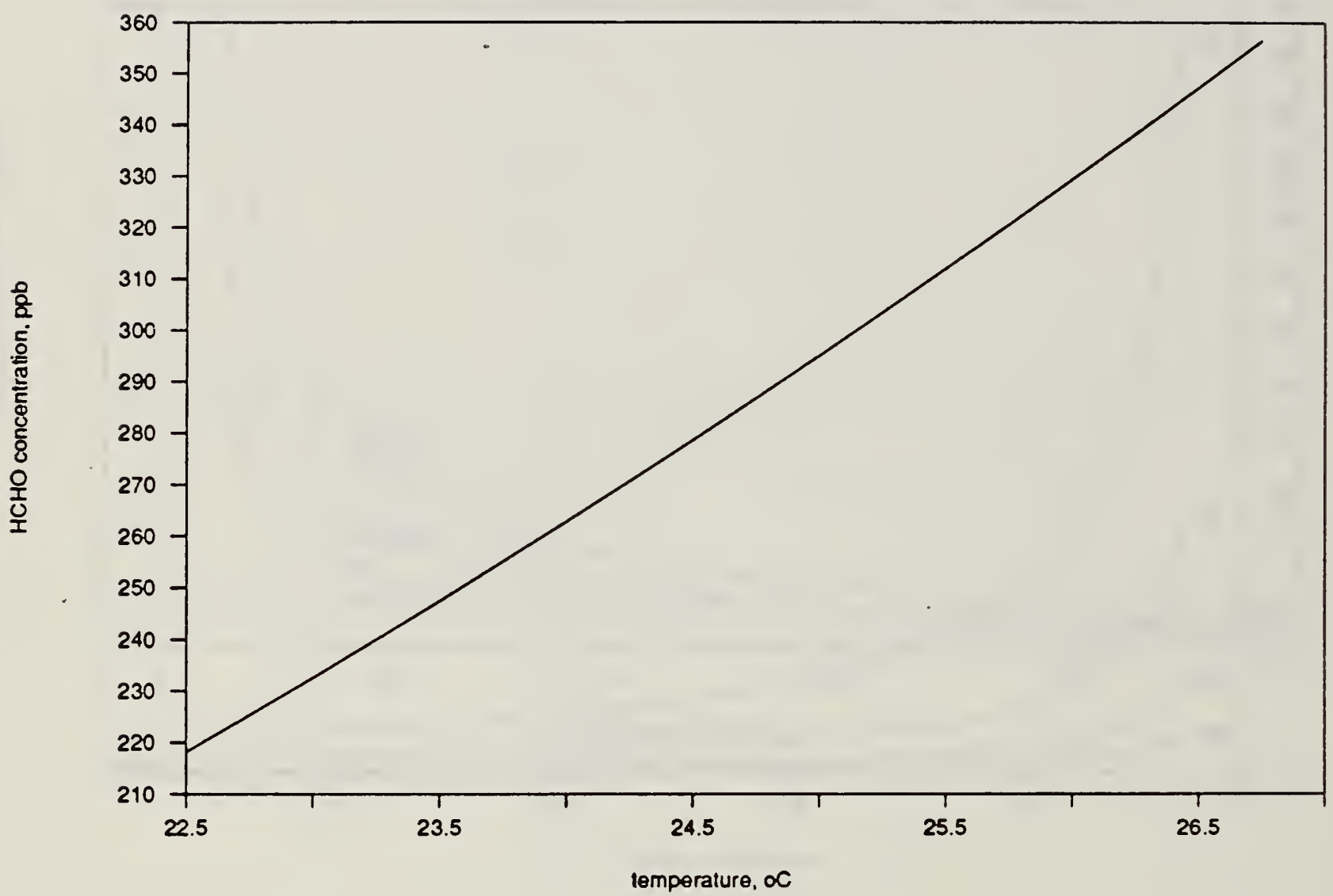

Figure 3. Sensitivity of chamber-test formaldehyde concentrations resulting from mdf to temperature. The relative humidity is $50 \%$, the air exchange rate is $0.5 \mathrm{~h}^{-1}$, and the mdf loading is $0.1 \mathrm{~m}^{2} / \mathrm{m}^{3}$. 


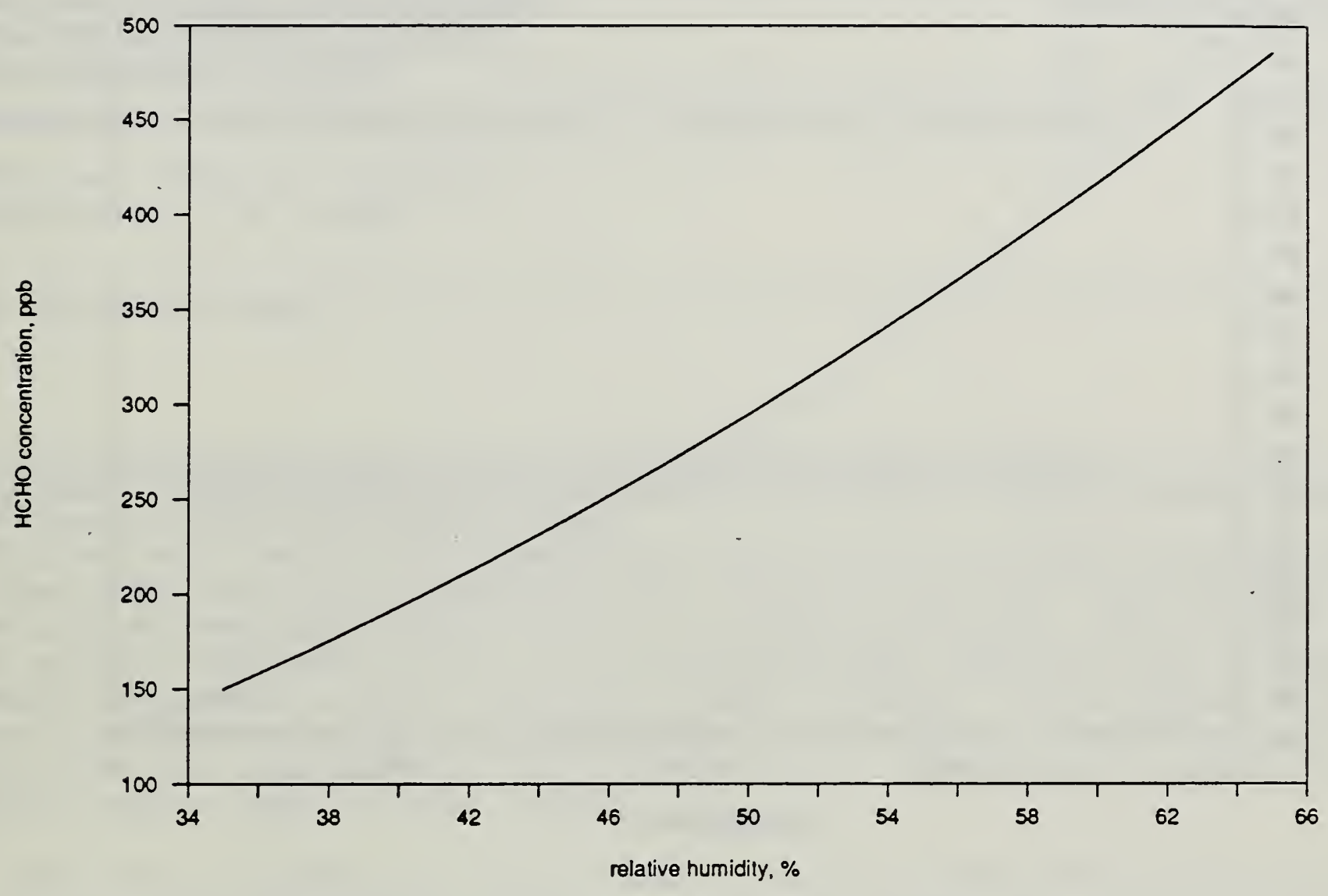

Figure 4. Sensitivity of chamber-test formaldehyde concentrations resulting from mdf to relative humidity. The temperature is $25^{\circ} \mathrm{C}$, the air exchange rate is $0.5 \mathrm{~h}^{-1}$, and the mdf loading is $0.1 \mathrm{~m}^{2} / \mathrm{m}^{3}$. 


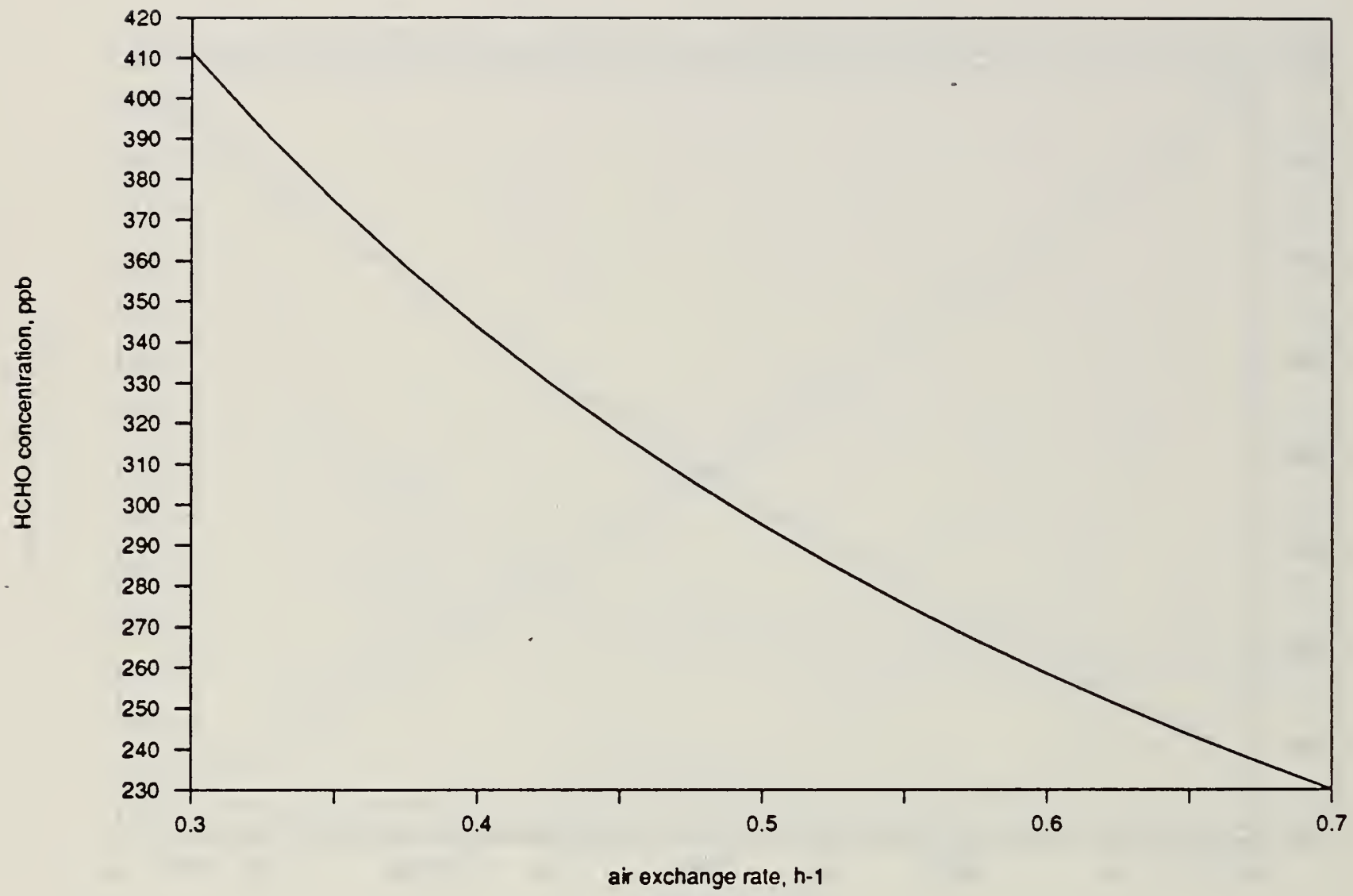

Figure 5. Sensitivity of chamber-test formaldehyde concentrations resulting from mdf concentrations to air exchange rate. The temperature is $25^{\circ} \mathrm{C}$, and the relative humidity is 508 , and the mdf loading is 0.1 
NBS-114A (REV. 2.8C)

U.S. OEPT. OF COMM.

BIBLIOGRAPHIC DATA

SHEET (See in structions)

1. PUBLICATION OR

REPORT NO.

NBSIR 88-3761
2. Performing Organ. Report Nof 3. Publication Date

MAY 1988

4. TITLE AND SUBTITLE

Predicting Formaldehyde Concentrations in Manufactured Housing Resulting From Medium-Density Fiberboard

5. $A \cup T H O R(S)$

SamueI Silberstein

6. PERFORMING ORGANIZATION (If joint or other than NBS, see instructions)

7. Contracd Grant No.

NATIONAL BUREAU OF STANDARDS

U.S. DEPARTMENT OF COMMERCE GAITHERSBURG, MD 20899

9. SPONSORING ORGANIZATION NAME AND COMPLETE ADDRESS (Street. City. State, ZIP)

National Bureau of Standards

Gaithersburg, MD 20899

10. SUPPLEMENTARY NOTES

Document describes a computer program; SF-185, FIPS Software Summary, is attached.

11. ABSTRACT (A 200-word or less factual summary of most significant information. If document includes a significant bibliography or literature survey. mention it here)

HUD previously issued Manufactured Home Construction and Safety Standards limiting formaldehyde emissions of particleboard and plywood paneling that were lanufactured using urea-formaldehyde resins for use in manufactured homes. This report uses indoor air quality models to predict how much medium-density fiberboard may be added to manufactured homes already containing maximum loadings of particleboard and plywood paneling, without raising the formaldehyde concentration beyond 400 ppb. It was found that any combination of mdf that results in a chamber-test concentration of $300 \mathrm{ppb}$ may be added to such a home.

A sensitivity analysis was done to predict how this formaldehyde concentration limit is affected by variations in temperature, relative humidity, and air exchange rate. It was concluded that limiting chamber concentrations to 200 ppb would allow for small errors in temperature, relative humidity, and air exchange rate that might be expected to arise in practice.

12. KEY WOROS (Six to twelve entries; alphobetical order; copitolize only proper nomes; ond seporote key words ty semicolons) formaldehyde, medium-density fiberboard, manufactured homes, indoor air quality, modeling.

13. AVAILABILITY

I Unlimited

E For Official Distribution. Do Not Release to NTIS

Order From Superintendent of Documents, U.S. Government Printing Office, Washington, D.C. 20402.

I Order From National Technical Information Service (NTIS), Springfield, VA. 22161
14. NO. OF PRINTED PAGES

\section{8}

15. Price

$\$ 9.95$ 


11 